\title{
LENGUAJE Y REALIDAD: UNA CONCEPCIÓN TRASCENDENTE DE LA POESÍA EN LA GENERACIÓN ESPAÑOLA DE 1970
}

\section{LANGUAGE AND REALITY: A TRANSCENDENT CONCEPTION OF POETRY IN THE SPANISH “GENERATION OF 1970"}

\author{
Joaquín MORENO PEDROSA \\ Universidad de Sevilla \\ jmoreno3@us.es
}

Resumen: Habitualmente se destaca en las poéticas de la llamada "generación del 70" su visión de la poesía como un discurso ficticio que no puede incidir en la realidad ni lograr una auténtica comunicación con los lectores. Sin embargo, algunos de estos autores creen que es posible reproducir en el poema la experiencia de la realidad y transmitirla a los demás. Los más representativos son Antonio Carvajal, Miguel d'Ors y Eloy Sánchez Rosillo. Este artículo expone y analiza su visión sobre el tema, a partir de las reflexiones metaliterarias que pueden encontrarse en sus textos teóricos y en su obra lírica.

Palabras clave: Novísimos. Generación del 70. Antonio Carvajal. Miguel d’Ors. Eloy Sánchez Rosillo.

Abstract: In the poetics of "the Generation of 1970" it is often highlighted the view of poetry as a ficticious discourse that cannot affect reality or achieve authentic communication with readers. Nevertheless, some of these authors think that the experience of reality can be recreated in a poem and then transmitted to people. The most representative poets of this conception are Antonio Carvajal, Miguel d'Ors and Eloy Sánchez Rosillo. This article presents and analyses their view on this matter, basing on the metaliterary reflection that can be found in their theoretical texts and in their poetry.

Key Words: Novísimos. Generation of 1970. Antonio Carvajal. Miguel d'Ors. Eloy Sánchez Rosillo. 


\section{INTRODUCCIÓN Y PROPUESTA METODOLÓGICA}

Dentro del panorama literario español, en la generación del 70 se suele incluir a los poetas nacidos entre 1939 y 1953, la mayoría de los cuales publicaron sus primeros libros alrededor de 1970. Tal vez por los riesgos inherentes al método de clasificación generacional (ver Mateo Gambarte, 2012: 148-153), uno de los errores más frecuentes por parte de la crítica ha consistido en extrapolar a la generación entera los rasgos de un pequeño grupo dentro de ella. Este grupo sería el de los nueve "novísimos" de Castellet, y otros autores de planteamientos afines. En sus primeros libros, los llamados "novísimos" hablaban de la realidad como si fuera un vacío distante, inaprehensible y sin sentido, manifestando su desconfianza hacia cualquier posible función o valor activo de la poesía (ver Barella, 1983: 71; Rubio, 1981: 76). A partir de 1970, algunos de estos autores iniciaron lo que se llamó una "etapa metapoética", indagando en la capacidad de la poesía para desvelar u ordenar la realidad, y reconociendo finalmente su inutilidad o fracaso. Es el caso del libro de Pere Gimferrer Els miralls (1970), los de Guillermo Carnero El sueño de Escipión (1971), Variaciones y figuras sobre un tema de La Bruyère (1974) y El azar objetivo (1975), los de Jenaro Talens El cuerpo fragmentario (1978), Otra escena (Profanación(es) (1980), Proximidad del silencio (1981) y Purgatori (1983), y también Canon (1973), de Jaime Siles. Otros "novísimos" iniciaron una "retórica del silencio", intentando que su poesía representara el vacío que constituye su única posibilidad; es el caso de Leopoldo María Panero, con Teoría (1973), o Félix de Azúa con Lengua de cal (1972), y Gimferrer coincidirá con ellos en 1977, con L'espai desert (ver Barella, 1983: 72). En ambos casos, como ha dicho Juan José Lanz, se concibe la poesía "como un modo de enfrentamiento entre realidad y lenguaje", que "nace de la constatación del fracaso del lenguaje para comunicar una experiencia vivida" (1997: 53).

La verdad es que la mayoría de los "novísimos", pasado algún tiempo, se fue distanciando de estas prácticas poéticas iniciales hasta abandonarlas por completo. Así, a partir de 1975, Julia Barella destaca que, en su mayoría, abandonaron una perspectiva autorreferencial de la poesía para volcarse "sobre la existencia de otra realidad" (1981: 5). Y, en la actualidad, son una minoría los poetas que siguen cultivando una estética basada en los iniciales planteamientos "novísimos". Sin embargo, bastantes críticos consideran que la visión de la poesía que tienen estos autores es la definitoria de todos los poetas de su generación. Por ejemplo, en fechas recientes Ramón Pérez Parejo ha escrito un exhaustivo trabajo, Metapoesía y crítica del lenguaje: de la generación de los 50 a los novísimos (2002), sobre el tipo de poesía que, a partir de cierto momento, empiezan a escribir algunos poetas del 50 y que, supuestamente, llevarán al extremo los de la generación del 70. Pérez Parejo acierta cuando dice que los poetas del 70 ponen en cuestión el valor de su propio arte, el sentido de la creación, el vínculo entre lenguaje 
y realidad, se distancian de su propia memoria y abordan la tradición con ironía. Sin embargo, la tesis fundamental de este libro es más radical. Según Pérez Parejo, las ideas de Jacques Derrida y Roland Barthes, que declaran la indeterminación del sentido en el lenguaje literario, y niegan la posibilidad de que el lenguaje se relacione verdaderamente con la realidad, conducen inevitablemente a la poesía contemporánea a referirse sólo a sí misma:

El texto es una danza de textos previos, de citas, referencias y mensajes de la cultura que se entrecruzan, se buscan o se repelen, lo que pone de manifiesto una diseminación constante, un estar fuera del origen, de un centro que no posee. Una vez perdido el centro, la búsqueda del origen se hace agónica e imposible (2002: 149).

Por esta razón, el escritor de la segunda mitad del siglo XX se enfrentaría necesariamente al lenguaje poético "en términos de crisis, de negación, de exilio y de silencio" (2002: 13). Como consecuencia de esta crisis, incluso el propio poeta acabaría desapareciendo en "la tradición previa, la recepción, la exégesis y el lenguaje que utiliza. La poesía se define entonces como práctica metapoética e indaga teóricamente en los estatutos que definen su ontología" (2002: 261). En los trabajos de otros críticos, el tema de las relaciones entre poesía y realidad aparece frecuentemente vinculado a una cuestión concomitante con él, como es la del "compromiso social", o cualquier otro tipo de "utilidad" o"función" que se atribuya a la literatura. Por ejemplo, en El compromiso después del compromiso. Poesía, democracia y globalización: poéticas 1980-2005, Araceli Iravedra destaca la preocupación de "la primera generación de poetas de la democracia" por "su sentido en un sistema social que cada vez parecía prescindir más de ellos", así como por el divorcio entre escritura y mundo contemporáneo. Esta preocupación sería un hecho diferencial con la generación anterior, la del 70, a quienes designa genéricamente como "novísimos", y a cuya poesía le atribuye una condición "gratuita, elitista y marginal" (2010: 20). Lógicamente, de unos autores que descreen totalmente de la capacidad referencial o comunicativa de la literatura no debería esperarse que le atribuyeran a su obra ningún poder transformador o revelador. Sin embargo, las manifestaciones que sobre esta cuestión han ido diseminando los autores "novísimos" y sus afines en textos teóricos y de creación son, con frecuencia, contradictorias.

En fechas muy recientes, Juan José Lanz ha intentado conciliar todos estos testimonios en Nuevos y novísimos poetas en la estela del 68. Aunque reduce su estudio a los poetas "novísimos" y "nuevos" (aquellos que no están incluidos en la antología de Castellet pero comparten una estética similar), caracteriza a toda su generación (que él llama "del 68 ") por "la concepción del lenguaje como único elemento capaz de llevar a cabo una 
ordenación de la realidad en el texto poético, capaz de construir una realidad autónoma en el poema" (2011: 35). Dada la incapacidad referencial de este, la oposición al sistema político imperante se haría a través de un "grado cero" de la escritura o "término no marcado", concepción recibida, una vez más, de Roland Barthes (Lanz, 2011: 64). Aunque resulte difícil de concebir la crítica en el lenguaje a las manifestaciones de una realidad que, como ya se ha dicho, no puede manifestarse en el lenguaje, Lanz ha conseguido ofrecer un resumen coherente de esa postura tan contradictoria:

El compromiso poético novísimo actúa fundamentalmente en el lenguaje, deconstruyendo la retórica del franquismo, resemantizando sus mitos, dinamitando la fundamentación histórica que lo justificaba y atentando directamente contra el discurso (como narración del poder) que los sustenta (2011: 155).

De un modo o de otro, la mayoría de estos trabajos termina por extrapolar a toda la generación del 70 los planteamientos iniciales de los"novísimos"y los poetas afines a ellos, especialmente en lo que se refiere a la incapacidad del lenguaje para desvelar la realidad, o para obrar una transformación de esta a través de sus lectores. Sin embargo, entre los coetáneos de los "novísimos" hay varios autores que, a lo largo de toda su evolución, han mantenido una trayectoria constante y personal, al margen de las "evoluciones" y "reacomodos" de la nómina castelletiana y sus semejantes. Estos autores comparten una concepción de la poesía como actividad basada en la propia vida, y una visión del lenguaje como sistema de signos referido a la realidad, a través del cual es posible lograr una verdadera comunicación con los demás, aunque sea de modo imperfecto. De entre estos autores, por su amplia producción poética, por las distinciones y premios recibidos, así como por su presencia habitual en el panorama crítico, se han seleccionado tres: Antonio Carvajal, Miguel d'Ors y Eloy Sánchez Rosillo. Además, la elección de estos tres autores viene motivada por las sustanciales diferencias entre sus respectivas ideas filosóficas, éticas y estéticas, en ocasiones radicalmente opuestas, que sin embargo no han impedido que lleguen a conclusiones muy similares en sus poéticas. A continuación, se expone y analiza su visión sobre el tema, a partir de las reflexiones metaliterarias que pueden encontrarse en sus textos teóricos y en su obra lírica. Los resultados se han dividido en dos secciones, la primera, referente a las relaciones entre literatura y realidad, y la segunda sobre la función que le atribuyen a su poesía. 


\section{LITERATURA Y REALIDAD}

\subsection{LITERATURA Y REALIDAD EN LA POÉTICA DE ANTONIO CARVAJAL}

El punto más importante que tienen en común las poéticas de estos tres autores es su concepción de la poesía como una actividad que brota de la experiencia vital, y que se desarrolla y evoluciona en contacto con el mundo, con una realidad cuyas referencias no se rehúyen ni se soslayan en el poema, sino que constituyen su materia fundamental. En varios lugares, Antonio Carvajal ha insistido en el hecho de que son las circunstancias de su vida las que alimentan y conforman su poesía, con frecuencia en forma de alusiones o elementos directamente importados de su experiencia cotidiana; de ahí que, para el poeta granadino, su obra y su vida sean dos realidades inseparables e interrelacionadas (García, 1999: 33; Torés García, 2002: 516). Esto explica también que la definición de poesía preferida por Carvajal tenga un carácter trascendente, al considerar que se trata de la expresión de "lo inefable" (1995: 9). Cuando, años más tarde, vuelva sobre esta definición, precisará más el contenido de ese objeto de la poesía, previamente contemplado, que se intenta representar en cada poema concreto, y se referirá a ella como la "fijación artística, mediante la palabra, del Bien y la Justicia y la Belleza y el Amor" (2001: 23). Finalmente, Carvajal recuperará su idea inicial de que estos valores son, en sí mismos, inexpresables, para concluir que la poesía no puede contenerlos, sino que debe conducirnos a una experiencia análoga a la que hizo que el poeta los entreviera. Por esta razón, explica que no puede considerar la poesía como algo "inefable", "expresión de lo inefable" o "lo inefable dicho", sino como "un 'decir' que nos aboca a lo inefable, como una más de las artes" (2002: 18). Llegados a este punto, sería necesario preguntarse por el origen o el escenario de donde procede la experiencia de esos valores inefables. La respuesta, según Carvajal, está muy clara: en el caso de un poeta que lee para nutrir su vida, no su literatura, la revelación de esas verdades últimas ha de proceder de la realidad. Y la poesía debe abocarnos a esa misma revelación:

Un poema se escribe para entender lo que nos dicen las cosas esenciales. Cuando el poema es lírico, las cosas esenciales son muy pocas: el amor y el desamor, la vida y la muerte, el hombre y el paisaje, la palabra y el silencio. $Y$ poco más (1995: 7).

Para Carvajal, la visión contemplativa del mundo tiene indudablemente un componente de admiración, de maravilla asombrada, y constituye una actitud humana esencial. De hecho, el poeta granadino piensa que la "reincidencia en el asombro" vendría 
a ser la "raíz primera de todo impulso humano hacia el conocimiento, la belleza, la poesía" (2000: 14). Por esta razón, la obra de Carvajal tiene como una de sus características más importantes la mirada que se vuelca sobre la realidad, sobre el paisaje y sobre la tradición artística, con la atención constantemente dirigida a sus semejantes y, en especial, al ser amado. Dentro de la más auténtica tradición romántica, sus sentimientos, ideas y experiencias se contrastan o identifican una y otra vez con elementos de la naturaleza o de su entorno, que vienen a confirmarlos o a negarlos. No se opone esta actitud con la habitual presencia del yo en sus poemas, ni con sus frecuentes referencias autobiográficas y la búsqueda de la emoción; en la mayoría de las ocasiones, se aprecia la voluntad de Carvajal por trascender el mero intimismo y ofrecer una visión más amplia, universalizada, de sus experiencias. El propio poeta declaraba esta voluntad en el poema al frente de su libro Siesta en el mirador, utilizando el neologismo "filaucia", de origen griego, para referirse al amor a uno mismo: "Acre filaucia/ me elevó del espejo hasta tu casa" (1983: 159). La elevación desde el espejo hasta la casa del lector, que simboliza el abandono de la mirada centrada en uno mismo para volcarse sobre la existencia de los demás, ya aparecía en su libro Casi una fantasía, en este caso en forma de la rotura del espejo (1983: 140); también puede encontrarse como momento inicial en el poema "Siesta en el mirador":

Mi rostro era un tormento.

Nube. Gajos de sol. Rompí el espejo.

Un rostro fragmentado. Y todo el cielo.

Dormir. Pasar. No desear. ¡Deseos,

ya para qué! Mis labios. Y el silencio.

Dormido entre los muros de este huerto.

Pasó un pájaro blanco, alegre, extenso.

Sus alas. Su gorjeo.

¿Es burla ver los pájaros en vuelo?

Pero yo no estoy preso.

Los bosques, crepitando. Los destellos.

Más allá no hay jardines. No los quiero.

Pájaros, bosques, mares, el espléndido

relato de inconstantes y viajeros.

Ángeles, no de llamas, sí de yeso.

Latir. Urgente azul. Estoy despierto.

Mi torre tiene un mirador y espejos.

Desde aquí miro y toco y gozo y siento. 
Su voz no amó Narciso. Amaba el eco (1983: 185).

De esta manera, se fragua uno de los símbolos más importantes de su poesía: el del mirador, un espacio abierto sobre el mundo y en contacto con él, pero que permite al mismo tiempo un refugio íntimo, ordenado y protegido de las zozobras y amenazas del territorio desconocido más allá. En este mirador, el poeta no está preso ni dormido: a través de todos sus sentidos, percibe la realidad y se siente vivir. También puede contemplar el mundo externo reflejado en su propia conciencia (los "espejos" que tiene su "torre"), conciencia que a su vez es capaz de contemplarse a sí misma; pero, en cualquier caso, lo que el poeta busca principalmente no es la representación de todo lo que contempla a través de la palabra (la "voz" de Narciso), sino su "eco": el efecto que su poesía, expresión de su conciencia íntima pero siempre referida al mundo exterior, llega a causar en los lectores. Por esta razón, Carvajal considera que "no se enamora de sí mismo Narciso sino del Otro, porque los otros son lo amable" (Guatelli-Tedeschi, 2004: 119).

\subsection{LITERATURA Y REALIDAD EN LA POÉTICA DE MIGUEL D'ORS}

En la poesía de Miguel d'Ors, la mirada sobre la realidad también ocupa un lugar esencial. De hecho, con frecuencia la actividad literaria aparece subordinada a la experiencia vital y a la contemplación del mundo. El poeta que, en su primer libro, oponía los recuerdos de la infancia del poema "Regreso" a "estos libros y libros y libros y más libros/ francamente tan llenos de tristeza" (1972: 46), en "Cerca del fuego" declarará con mayor firmeza: "Los libros no me sirven/ si no me dejan contemplar la hierba" (2001: 81). En la teoría literaria del autor gallego, la obra artística crece orgánicamente desde la propia vida y alrededor de ella, aunque manteniendo su índole lingüística y sin confundirse mutuamente; por eso, entre las pocas definiciones que d'Ors ha establecido como esenciales en su poética destacan "que la Poesía es cosa de lenguaje, que en ella vale todo (cuando vale) y que es algo que brota de la vida" (1999: 93). Se trata de una concepción de la poesía y el lenguaje que está muy lejos de las poéticas de sus coetáneos "novísimos" y afines, cuya visión hermética y autónoma del lenguaje convertían al poema en un objeto cerrado sobre sí mismo e incapaz de señalar o actuar sobre la realidad. Sin negar la naturaleza exclusivamente lingüística de la literatura, el mismo Miguel d'Ors exponía su visión referencial del lenguaje y la poesía en una encuesta al frente de sus poemas, en la antología Las voces y los ecos:

Yo pienso que la poesía, que puede servir para mil usos que van desde conquistar a una mujer, insultar a los enemigos de uno, desahogarse en las penas o halagar a algún poderoso hasta contribuir al derrocamiento de un 
gobierno o a una campaña benéfica, sólo puede definirse y evaluarse en el plano del lenguaje. Ahora bien: me resulta imposible concebir la poesía como "una construcción lingüistica autónoma" porque en la misma naturaleza del lenguaje está el no ser autónomo, el remitir a la realidad. Toda palabra significa algo, lleva consigo algo de la realidad; tanto de la interna del hablante como de la exterior a él. Esto supone, en definitiva, que disponer unas palabras sobre un papel es también "comunicar un contenido anímico en toda su especifidad", conocer la realidad, etc. [...] Por mi parte, desde 1975 concibo cada poema mío como algo que es simultáneamente una construcción lingüistica, un desahogo, una confidencia y un acto de Amor (García Martín, 1980: 132-33).

Que la poesía lleve consigo algo del mundo, que nos permita conocer la realidad, es lo que ambiciona su autor, lo que se debe esperar de él; en el poema "Solamente una cosa", d'Ors dice que a los poetas sólo hay que exigirles, "en la lengua que quieran,/ que digan lo imposible" (2005: 9). Naturalmente, ésta es la meta; y ese "imposible" es el mismo misterio "inefable" de Antonio Carvajal: la propia realidad. Sin embargo, sería una ingenuidad pensar que los objetos y experiencias del mundo son contenidos que se pueden trasvasar íntegramente al poema, y que como tales han de llegar al lector. Bien por la incapacidad del poeta, bien por los límites que le impone el propio lenguaje, la comunicación literaria será siempre necesariamente imperfecta. El autor gallego es muy consciente de esto, lo que le ha llevado a afirmar que "también es síntoma de confianza con la Poesía la capacidad de percibir y aceptar, en los poemas que uno compone, las limitaciones del propio talento" (2010: 8). Éste es el asunto del poema "Resignación", una de las muchas posibles poéticas de Miguel d'Ors. En él se describe el claro de un cielo primaveral que se ha abierto sobre un tramo de carretera campestre, cerca de Paraños (Pontevedra). Como final paradójico, inmediatamente después de esta descripción, el autor termina el poema con una reflexión metaliteraria sobre los límites del propio arte, que rebajan o niegan -sólo parcialmente, claro- lo que él mismo acaba de hacer:

Sé que querré decir todo esto en un poema, y séque, cuando lleguen, las palabras pondrán sobre la fuerza de esta luz y estos colores una veladura de rutina impotente, y que al fin no estaré diciendo lo que diga, pero hace muchos años ya que dejé de ser poeta joven y sé muy bien que no hay más cera que 
la que arde en esta lengua. Con la edad uno aprende a fracasary a hacer de la resignación una poética (2010: 47).

\subsection{LITERATURA Y REALIDAD EN LA POÉTICA DE ELOY SÁNCHEZ ROSILLO}

Por lo que respecta a la poesía de Eloy Sánchez Rosillo, el sentimiento de unión con la naturaleza y la indagación sobre dicho vínculo misterioso son dos temas centrales. En el poema "Casta diva" se ofrece una visión de la realidad como armonía, en una metáfora de inspiración pitagórica según la cual los objetos de la naturaleza están unidos y se mueven acordemente de acuerdo con un patrón musical. De esta base rítmica común procede la unión inefable que el poeta experimenta con la realidad: "Mi vida estaba unida a la verdad del mundo/ por un hilo secreto./Y en mi sangre latía la música que mueve/ a la gran muchedumbre de los seres creados" (1995: 213). Esta armonía musical constituye también el origen de la actividad poética. Cuando, años más tarde, el autor murciano reflexione sobre la naturaleza de su vocación, la misión de escribir poesía tendrá como objeto la percepción y transmisión de esa música, en una suerte de traducción de la cadencia cósmica al esquema rítmico de la versificación: "Todas las cosas tenían un ritmo en su ser, que era el que las hacía vivir e integrarse en el universo, y poco a poco quizá lograra yo decir en mis versos ese ritmo que ya oía, que ya sentía en el alma y en el cuerpo" (2005a: 23). Parece apuntarse aquí una concepción del poeta como vidente privilegiado, o intérprete místico de las relaciones ocultas que se desarrollan en el interior de la realidad. Sin embargo, Sánchez Rosillo comparte la misma visión que Carvajal y d'Ors sobre las limitaciones del lenguaje y del autor. Aunque el poeta pueda percibir ese ritmo en el ser de las cosas, la esencia de éstas siempre permanecerá fuera del alcance de las palabras, rodeada de misterio: la única posibilidad que le cabe al escritor es la de aproximar lo más posible su expresión a este misterio. Así se desprende del poema "Límites":

Las palabras tantean inseguras, acercan realidades distintas como en un parpadeo y al cabo las alejan por aproximación. Límites del decir, en los que sólo crecen las adustas retamas de la melancolía; soledad que es misterio; silenciosa sustancia ensimismada y última que no quiere ser dicha y que calla en el íntimo corazón de las cosas (2008: 48). 
Estas limitaciones del oficio poético no deben entenderse como una derrota absoluta; frecuentemente, lo que la poesía dice está más allá del propio lenguaje, y hasta ese punto limítrofe debe llevarlo el poeta, no para que exprese el misterio mismo -lo cual es imposible-, sino para que conduzca al lector a la experiencia de éste. Sánchez Rosillo parece reconocerle a la poesía ese valor y ese poder cuando le suplica, en la composición titulada "Ruego", que sus poemas "digan/ algo más que palabras, palabras y palabras" (2008: 149). Por otra parte, el autor murciano no considera que la inefabilidad de lo percibido deba redundar en una expresión rebuscada y hermética. Si la realidad es, en última instancia, incognoscible, también es verdad que su misterio se manifiesta con claridad ante nosotros, cotidianamente expuesto y a nuestro alcance.

Por tanto, la poesía, según Sánchez Rosillo, debe proceder con fidelidad a este modelo: "La vida es compleja y misteriosa, pero es a la vez transparente y nítida. Así es también la poesía que prefiero leer y la que siempre he intentado escribir. La oscuridad sin porqué en cualquiera de las artes me parece un engañabobos". De no ser así, en caso de renunciar a comunicar lo incomunicable, la poesía podría "adelgazar hasta caer en la anorexia y quedarse en los puros huesos", una tendencia que el poeta murciano aprecia en "Ios minimalismos, misticismos de pacotilla y demás ocurrencias macrobióticas actuales", en cuyos poemas echa en falta también "su carnalidad, su sensualidad" (2005a: 34). Evidentemente, al hablar así Sánchez Rosillo se está refiriendo al "minimalismo poético", "poesía del silencio" o "conceptualismo" que, por inspiración mallarmeana, inauguraron algunos autores novísimos y sus coetáneos en los años 70, y que prolongó su presencia en la poesía española hasta, aproximadamente, diez años más tarde (ver Amorós, 1989: 66; López, 1990: 44). El inconveniente que el poeta murciano le ve a tales poéticas es que no permiten que el lector participe de lo que el autor ha visto y de la emoción que ha sentido al verlo, y en vez de eso consiguen "que no vea ni entienda nada o perciba algo por completo distinto a lo que contemplaste" (2005a: 35). Para Sánchez Rosillo, en cambio, la poesía es el mejor medio para comunicar la experiencia o intuición de la realidad, ya que no su conocimiento:

El escribir poesía es para mí una manera de entender y de considerar la vida, de acercarme a ella y de confundirme con su sustancia; un ser y un estar. [...] Percibo las cosas del mundo a través de la poesía, que no es en modo alguno el reino de lo subjetivo, de lo neblinoso e indeterminado, de lo arbitrario, sino la posibilidad de aprehensión de la realidad más rigurosa, lúcida y comprensiva que conozco. No escribo para explicarme el misterio del mundo -los misterios no tienen explicación-, sino para participar de él, para formar parte del corazón de ese misterio (2005a: 25). 


\section{FUNCIÓN DE LA LITERATURA}

\subsection{FUNCIÓN DE LA LITERATURA EN LA POÉTICA DE ANTONIO CARVAJAL}

La influencia que la literatura tiene sobre la vida comienza, para Antonio Carvajal, en su experiencia como lector. Según el poeta granadino, las lecturas le sirven, no para evadirse ni para construir su poesía a partir de ellas, sino para ampliar su experiencia de la vida y ayudarle a definir una visión personal de la realidad. De esta manera, la lectura le permite trascender el entorno limitado en que se desarrolla su existencia cotidiana (Chicharro, 2002: 212-13). La continuidad que se da entre sus lecturas y su vida se prolonga en su obra poética, y en la función que le atribuye; por el afán de mantener esta coherencia entre vida y obra, Carvajal siempre se ha considerado un poeta moral (Torés García, 2002: 515). Desde sus primeros libros, el autor granadino concibe la poesía como algo más que una representación de la realidad; para él, es un instrumento de conocimiento y de transformación. Así se ve en la nota introductoria a Servidumbre de paso: "No he situado un espejo junto al camino, sino una lente: vida y verbo, en ocasiones, me han enardecido, y aquí están los resultados de aquellas quemaduras" (Carvajal, 1982: 5). La poesía sería esa lente que, por un lado, sirve para obtener una visión aumentada de la realidad; y por otro, puede concentrar los rayos de luz en un solo punto incandescente. Los poemas se corresponderían con las quemaduras producidas por esa confluencia de vida y visión poética. Sin embargo, cuando Antonio Carvajal se ha referido a la función de su poesía, el punto de vista que ha adoptado con más frecuencia es el de considerarla como una fuente inagotable de serenidad, alegría y consuelo. Así lo encontramos en Sol que se alude, colección de poemas escritos entre 1979 y 1981, en el titulado "A la poesía", que trata de evocar el himno litúrgico "O, quam amabilis es...":

¡Oh, júbilo del corazón, solaz de la mente! Pon tu mano sobre esta frente cansada y dale íntima placidez y suave quietudy paza su sangre.

Oh, amable, dulce y piadosa: pues tú no eres de aquellos que venden la misericordia, mira con tiernos ojos al que te llama con esperanza, 


\section{si no con fe; dale el refugio \\ de tu benevolencia y deja \\ le que suspire ollore cuanto \\ necesite, para cobrar contigo \\ su alegría (1983: 260).}

Este poema da cuenta de la trascendencia que tiene la poesía para Carvajal. El poeta granadino se refiere a ella no sólo a través de una personificación, sino en los mismos términos que se utilizan para dirigirse a la divinidad. Con una crítica de soslayo a la hipocresía de algunos ministros religiosos ("aquellos que/ venden la misericordia"), el autor se dirige a la poesía "con esperanza,/ si no con fe", para que sane su sufrimiento y recobre la alegría. La conclusión es clara: la poesía desempeña para Carvajal el mismo papel que la religión para los creyentes, en su doble vertiente de moral y consuelo. En otras ocasiones, la poesía será el principal medio de unión con los seres queridos y con la naturaleza; de ahí que el autor le encomiende su salvación en el poema "Si alguna vez perdiera la esperanza":

Si alguna vez perdiera la palabra,

que es hoy mi sustento, el solo bien

que me permite unirme a los que amo,

amiga mía, canta y háblame.

\section{Canta con esa voz que has aprendido}

de cada arroyo y cada amanecer,

y tiéndeme tu mano hacia mañana:

Sálvame, amiga mía, sálvame (1993: 57).

En estos versos se apunta la idea de que, para Carvajal, el principal consuelo que proporciona la poesía es la comunicación con los demás ("el solo bien/ que me permite unirme a los que amo"). No se trata, entonces, de una delectación narcisista en el propio talento o en la perfección de unos artificios creados mediante la palabra. La relación entre vida y obra, la mirada sobre la realidad, la expresión de lo inefable y el afán comunicativo forman parte de una necesidad más perentoria, que da lugar a una de las definiciones más claras de su pensamiento literario:"Mi poética está muy clara: salvarme del vacío intentando salvar la belleza" (Torés García, 2002: 512). El consuelo, la única salvación del poeta está en la transmisión de lo contemplado. Ya en el poema-dedicatoria de Serenata y navaja, Carvajal le había atribuido a la vocación poética el mismo impulso que al lúgano -pájaro que imita el canto de otras aves-, el de aspirar a la comunicación total, a la comunión de la belleza: “Sí, el corazón es lúgano, produce un eco, desdobla nuestras vidas: significa una entrega" $(1983,69)$. El deseo de aprehender la realidad y participar de su misterio, y el de comunicar esa experiencia de lo inefable a los demás se ven cumplidos, simultáneamente, 
en la poesía. Ese vínculo entre contemplación y comunicación le proporciona todo su sentido, amplitud e intensidad a la visión poética de Carvajal:

¿No es la poesía, y más la lírica, el máximo acto social, la transmisión de una vivencia hondísima, altísima, que nos afecta y hacemos nuestra porque nos atañe en lo que consideramos más humanamente verdadero de nosotros mismos? Y por eso precisamente, ¿no nos sentimos más plenamente unidos con los seres que nos rodean, con las cosas esenciales [...], cuando la poesía nos mejora en nosotros mismos? [...] la condición social del poema siempre exigirá una corporeidad sonora imprescindible (1995: 8-9).

El logro de esa "condición social" del poema sólo se alcanza cuando logra afectar al lector en toda su integridad, obrando simultáneamente sobre sus sentimientos, su inteligencia, su voluntad y su imaginación, transmitiéndole una revelación análoga a la experimentada por el autor, si bien en este caso originada por la recreación artística. Por esta razón, Carvajal se ha negado a buscar con su poesía un "asentimiento fácil", "sin calado en las almas próximas y ajenas", en vez de un verdadero estremecimiento (2001: 23). En varias ocasiones, el poeta granadino ha identificado ese "estremecimiento" con la emoción. Para Carvajal, la emoción vendría a ser una turbación interior que implica en su efecto a todas las potencias psíquicas del lector, mediante un asentimiento intuitivo, instantáneo y no mediado por la lógica, a lo que se dice en la obra: "lo que se tiene es el reflejo inmediato, casi con simultaneidad de espejo, de lo que se ha puesto en el poema... sí, es una respuesta inmediata" (Guatelli-Tedeschi, 2004: 203). La finalidad de esta emoción sería recrear en el lector la Belleza percibida por el autor. Según Carvajal, la belleza tiene un poder redentor que él mismo quiso transmitir a los demás con su poesía, y para ello se propuso construir con su obra "un reino de belleza, sensorial y moral" (2004a: 13) que sirviera de consuelo y referencia para los hombres de su tiempo. Esta visión de su quehacer poético, no exenta de idealismo, explica el rechazo del poeta granadino hacia las estéticas feístas, la expresión de lo soez, lo cruento o malvado en el poema, que para Carvajal vendría a constituir una rendición ante el mal (2004b: 21).

Por todas estas razones, el autor granadino reconoce en su poesía el "afán de mostrar y de salvar, transmitiéndolos, determinados valores: el respeto al valor de la persona, la lealtad, la libertad en convivencia" (Guatelli-Tedeschi, 2004: 251). En última instancia, más que conseguir el ordenamiento de la realidad o su comprensión profunda, lo que Carvajal le pide a la poesía es que le haga el mundo más "vividero": que le proporcione consuelo, que lo anime con su palabra y le devuelva la fe en la capacidad del hombre para obrar el bien y construir un futuro mejor, y que preserve los valores que él considera fundamentales en su vida: la compañía del amor y la amistad como refugio y estímulo 
ante las adversidades, y el arte "como la vía perpetua de mejora personal y colectiva" (2004b: 34). Esta visión es la que Carvajal ha pretendido expresar en su poesía, y a través de ella transmitirla a los demás hombres:

De todos mis anhelos de juventud, uno persiste: Un día leí que Clemenceau propuso adquirir el conjunto de todas las "Ninfeas" de Monet, que se ofrecerían al pueblo francés como bálsamo para las heridas que sufrió en la Gran Guerra europea. El arte puro no como olvido del mundo sino como solución para sus males: ésa es la gran tarea, ésa es mi gran tarea: dar a los demás lo mejor de mí mismo de la mejor manera que sé hacerlo. Si vale poco, si mi poesía no logra la rara virtud de fundar una esperanza, una alegría, un consuelo, una certeza vital en algún corazón fraterno, sepan que se deberá a mi falta de talento, no a miseria moral o a noluntad en mi entrega (2004b: 35).

\subsection{FUNCIÓN DE LA LITERATURA EN LA POÉTICA DE MIGUEL D'ORS}

Miguel d'Ors comparte con el poeta granadino la experiencia de la poesía como fuente de confortación y consuelo. Más que "como poeta, mago, místico, sacerdote o redentor social", el autor gallego dice tener una visión del poeta como "arriero": "cantar sencillamente para entretener, para mantener despierto, para dar compañía y ánimo a ese otro que es uno mismo durante el viaje a través de la noche" (2008: 189-90). Y es que, para Miguel d'Ors, lo que subyace frecuentemente en el trato con la literatura, como lector o como autor, es un sentimiento de insatisfacción con la realidad: "a menudo pienso que se escriben versos por un déficit de felicidad" (2005: 7). Este poder de la poesía para aliviar las tribulaciones de la vida es un motivo que aparece con frecuencia en las composiciones metaliterarias de d'Ors. En "Canción", por ejemplo, un día lleno de contrariedades puede redimirse si el autor encuentra la inspiración necesaria para terminar un poema humorístico, basado precisamente en todos los obstáculos y dificultades que han jalonado la jornada. El poder catártico de la creación artística hará que el poeta concluya su narración en un estado opuesto al esperado: “Feliz. Oh Poesía, poder que nos permites/ echar todas las sombras fuera del corazón/y de un día que empieza tan coñazo/ hacer una canción" (1999: 49). Esta capacidad de la poesía para reconfortar el ánimo y devolver la alegría desempeña un papel fundamental en la poética de Miguel d'Ors, hasta el punto de que prácticamente cualquier otra consideración se subordinará a ella. Desde una perspectiva muy similar a la de Antonio Carvajal, el autor gallego considera la emoción como piedra de toque de la auténtica poesía, y frente a este criterio 
quedaría invalidada cualquier poética o teoría literaria, sin importar su modernidad o su grado de elaboración científica. Así es como lo plantea d'Ors en el poema "Cuestión de nombres (defiende a Pablo Neruda de un pedante)":

"No es poesía -dices mientras clavas

las uñas en tu negro tratado de Semiótica-

una simpleza como

'Puedo escribir los versos más tristes esta noche".'

Poesía no será, pero cuántos y cuántos

miles de corazones han temblado

bajo la innumerable mirada de los astros

con la maravillosa no-poesía

de los incomparables no-poemas

de aquel gran no-poeta paisano de la lluvia (1994: 48).

Comentando estos versos, Enrique García-Máiquez ha concluido con acierto que d'Ors "valora la poesía en la medida en que entra a formar parte de sus sentimientos y configura su vida" (2001: 14). Pero el mismo criterio de valor que utiliza el poeta gallego con sus lecturas es el que determina la función que le atribuye a su obra. Si, en la nota final de su libro Hacia otra luz más pura, d'Ors consideraba que la poesía tiene su origen en la vida misma, no dejaba de añadir que "tiene también la vida como destino", y precisaba: "La de usted, lector. Espero haberle ayudado a mejorarla un poco haciéndole pasar un buen rato" (1999: 93). Se trata de una visión de la literatura según la cual la obra alcanza su cumplimiento en el lector, satisfaciendo una doble función. La primera, proporcionar a los demás esa compañía, ese entretenimiento y ese ánimo que el autor a su vez había recibido de sus lecturas. La segunda, transmitir la belleza que el autor ha querido dejar consignada en su obra y, multiplicada en la conciencia de sus lectores, rescatarla del tiempo y hacerla inmortal. Ésta es la visión que podemos encontrar, por ejemplo, en uno de los varios poemas que Miguel d'Ors ha titulado "Posible arte poética": "Acaso sólo escribo para que algún desconocido, en algún sitio, se haga cargo de alguna de estas cosas/ y tanta hermosura no se confunda con la nada cuando yo ya no esté aquí para decirla" (2001: 87). Esta doble función es esencial en su concepción poética, porque determina de modo fundamental el acto mismo de la creación literaria.

Se trata de una perspectiva que tiene su origen en las ideas poéticas de Edgar Allan Poe, y a ella le atribuye d'Ors la importancia histórica del autor norteamericano. Más que el desahogo sentimental, más que la propia satisfacción ante la obra terminada, es la atención al lector la que exige un dominio extremado de los recursos técnicos de la escritura, y un conocimiento preciso de su posible efecto; ya que, de no lograrse éste 
de un modo fiel a la experiencia que le dio origen, no se podría transmitir la belleza contemplada, ni suscitar la misma emoción en el lector. Así que la emoción no sólo sería el criterio escogido por d'Ors para valorar sus lecturas, sino también para juzgar el logro de sus propias composiciones. Así lo expone en sus Virutas de taller:

No se trata, por consiguiente, tanto de expresar emociones como de provocarlas en el lector. [...] Y esta atención a la emoción del lector supone preocuparse, antes que por el lector mismo, por el texto que él va a leer: es preciso garantizar su buen funcionamiento, y para ello es imprescindible tener un perfecto control sobre su elaboración, seleccionar el vocabulario, la métrica la sintaxis, las imágenes, todo, en función del efecto perseguido. La creación de un poema es desde entonces una verdadera mise en scène.

Todo esto es verdad siempre que no se olvide que para producir un determinado sentimiento en el lector es condición indispensable conocer ese sentimiento, es decir, haberlo experimentado. De lo contrario, "apaga y vámonos" (2008: 28).

El logro de la emoción no es un proceso sencillo o automático. En ocasiones, está destinado al fracaso, y el mismo Miguel d'Ors ha descrito ese fracaso en algunos de sus poemas. En “Palabras. Nada”, por ejemplo, el poeta reúne, en su "noche sola y extranjera”, "unas palabras torpes, agrupadas/ para salvar -ilusas- la distancia". Sin embargo, el artificio no logra su efecto, pues la solitaria y áspera realidad acaba imponiéndose al poder consolador de la remembranza, y al autor sólo le queda "tinta sobre papel. Palabras. Nada" (2001: 213). Sin embargo, habría que decir, como ya se hizo al hablar de la representación de la realidad en el poema, que las limitaciones de la poesía o del propio talento no conducen a una derrota absoluta. En este caso, el autor ha conseguido llevar eficazmente al poema la triste emoción de su fracaso, y de ahí tanto él mismo como el lector pueden obtener algo de consuelo, al sentirse identificados o acompañados. Gracias a este poder, el intento fallido se acaba convirtiendo en una victoria.

El autor gallego le reconoce a la poesía el poder de influir en su realidad y en la de sus lectores, atribuyéndole abiertamente una función trascendente a la creación poética. Como decía en el prólogo de su libro Sol de noviembre, en sus versos "el lector y él mismo, como en una fogata de hojarasca medio mojada, pueden entibiarse un poco las manos". Y el origen de ese poder transformador de la poesía vendría, precisamente, del valor referencial, significativo, del lenguaje, que lleva consigo algo de la realidad: “No se sabe si por el pequeño pálpito de verdad y belleza que tienen aún algunas palabras o si por la compañía que traen: amores, amigos, lugares, momentos..., la vida" (2005: 8). Sin embargo, en otros lugares Miguel d'Ors le ha atribuido a su poesía un poder más radical: 
el de ofrecer un vislumbre, como un reflejo apenas entrevisto, de la divinidad. Esta concepción es de extrema importancia en un poeta que con frecuencia se ha declarado católico en sus poemas. El Dios del Nuevo Testamento, que es Amor, es también el supremo Bien, la suprema Verdad y la suprema Belleza. Teología, religión y arte vendrían a confluir en una poesía que se quiere humilde transmisora de esa fe. En el poema "De fuegos y buitres", la poesía sería "algún que otro reflejo vacilante/ de la Verdad de un Dios que no es un mito/ sino un Amor sin fin". Ese atisbo, a pesar de su debilidad, le serviría al poeta "para alumbrar un poco/ mi ruta por el tiempo" (2010: 48). El consuelo ofrecido por la poesía, de este modo, sería una participación del Amor divino, de la misma manera que la belleza perseguida por el arte es un fragmento o reflejo de la Belleza misma. En última instancia, en la cosmovisión católica de d'Ors, el objeto último de la poesía es Dios, la revelación de Su rostro. De forma definitiva lo ha expresado el autor gallego en un poema cuyo título es la definición platónica de belleza, "Splendor veritatis":

Tu rostro, que aparece-un relámpago-y que desaparece. Muero buscando entre palabras apagadas un ascua de verdad que ilumine un instante ese rostro. Haberlo casi visto -un reflejo en el río- y vivir solamente para volver a verlo. Que aparece-un relámpagoy que desaparece. Qué dolory qué gozo este mover palabras, materia que se cierra con espesor de piedra sobre Tu luminosa permanencia, o que logra un destello, o siquiera nos permite ese leve temblor de Tu inminencia bajo la piel de un verso. Es esto la poesía: buscar en las palabras Tu rostro, que aparece -un relámpagoy que desaparece (2001: 196).

\subsection{FUNCIÓN DE LA LITERATURA EN LA POÉTICA DE ELOY SÁNCHEZ ROSILLO}

Por lo que respecta a Eloy Sánchez Rosillo, el autor murciano le concede a la poesía un papel esencial en su vida. En primer lugar, la vocación poética ha conformado su modo de ser y de estar en el mundo, imbricándose estrechamente con su propia identidad. Por eso, Sánchez Rosillo considera que "yo soy yo gracias a los libros que he escrito". Fiel a su concepción de la poesía como un don recibido, que arrebata las facultades del elegido y determina su destino para siempre, a Sánchez Rosillo le gusta repetir que son sus libros los que le han hecho a él, y no al revés: “Les debo muchísimo, pues, y les estoy agradecido, 
a pesar de sus incontables imperfecciones"(2005a: 18). Pero, también, la vocación poética ha moldeado su relación con el mundo, haciéndole vivirlo con más intensidad, como si lo descubriera por primera vez: “La realidad entera era nueva para mí tras aquella revelación. La luz brillaba más, el mundo olía de otra forma. Pasaba los días y las noches entregado a mi quimera, al sueño hermosísimo de verlo todo a través de la poesía"(2005a:22). A la hora de explicar con más precisión el modo en que la poesía es capaz de influir sobre la vida, Sánchez Rosillo no hace distinciones entre la experiencia de aquélla como lector o como autor: cuando cualquiera de los dos la vive con autenticidad, la poesía le "proporciona a la existencia una intensidad excepcional y la limpia de banalidades". Esta intensidad viene dada por la mirada contemplativa sobre la realidad, que es consustancial a la actividad poética: a través de ella nos liberamos del ruido y la intrascendencia, podemos escapar del ritmo frenético que frecuentemente adopta nuestra existencia cotidiana, y tomamos consciencia del hecho de estar vivos. De esta visión más profunda y sosegada sobre la realidad proviene el efecto de la poesía, que es, ante todo, un efecto moral:

La poesía no soluciona ni al individuo ni a la colectividad los problemas diarios de la vida (la injusticia y toda la miseria que de ella se deriva, por ejemplo), ni da respuestas concretas y unívocas a las grandes preguntas existenciales (el porqué del amor, del odio, de la soledad, de la muerte), sino que nos pone en contacto con los enigmas del vivir y nos anima a mirarlos de cerca, a meditar sobre ellos y a adoptar consecuentemente actitudes y conductas. Semejante ejercicio moral transforma al individuo, hace surgir en él a alguien que no era antes y lo mejora como ser humano (2005a: 25-26).

Si tal es la transformación que la poesía obra en el lector, aspirar a producirla como autor comporta una serie de exigencias específicas. Según Sánchez Rosillo, la primera de ellas sería el distanciamiento respecto a las propias experiencias, y la voluntad de convertirlas en algo que trascienda la propia individualidad: "es preciso que el material autobiográfico se universalice y se transforme en algo independiente de uno mismo". Si esto se logra, la experiencia del poeta será susceptible de ser compartida por los lectores, "que podrán ver en mis versos con cierta sorpresa su propio rostro como en un espejo, y que por consiguiente tendrán la posibilidad de reconocerse allí sin dificultad"(2005a: 31). Esta exigencia de universalizar la propia experiencia, en realidad, no sería un requisito accesorio que se añade a la creación poética, sino una consecuencia inevitable de su propia naturaleza. Por su concepción de la poesía como un don que el poeta recibe de una instancia superior, el autor murciano ve la escritura como un legado que se le entrega a él en primer lugar, y que después él debe entregar a los demás. En su poema 
"Las palabras que he escrito", Sánchez Rosillo declara que "las palabras que he escrito no son mías": "Yo escuché, y dije luego/ con mi voz y a mi modo lo que oí".

La función comunicativa de su poesía, por tanto, se funda en su origen como revelación; lo revelado no pertenece exclusivamente al poeta, sino que exige ser ofrecido a los demás como a él se le ofreció en primer lugar: "Qué raro patrimonio. [...] Se halla a disposición de todo el mundo;/ en verdad es de todos" (2005b: 37-38). Tres años más tarde, en su libro La certeza, se referirá con más precisión a la experiencia autobiográfica universalizada (la "esperanza", el "miedo", la "soledad") y a la revelación (la "luz") como fundamento de esa vocación esencialmente comunicativa de la poesía, dentro de la composición titulada "Para que tú las oigas": "Son míos y son tuyos/ su esperanza y su miedo,/ la soledad que tienen,/ la luz que llevan dentro" (2008: 21). Lo verdaderamente llamativo es que, desde su particular postura, Sánchez Rosillo ha llegado a la misma conclusión que Antonio Carvajal y Miguel d'Ors respecto al criterio por el que puede saberse si un poema es auténtico y si ha logrado cumplir con su objetivo: este criterio es la emoción.

Para el autor murciano, lograr un poema emocionante es algo que implica todas las facultades del autor. Si no hay emoción, no se tratará más que de un ejercicio de la inteligencia, del esfuerzo, del ingenio o de la técnica, pero no será un verdadero poema. Sánchez Rosillo se ha referido a algunos de sus contemporáneos aludiendo a que conciben la poesía como un juego, como un pasatiempo principalmente lúdico. Según él, tal enfoque es lícito, "y los resultados de tal actividad podrán ser graciosos, bonitos, curiosos, sugestivos, intelectualmente atractivos, pero sólo eso, en el mejor de los casos" (2005: 30). La emoción no es únicamente una efusión psicológica o un desahogo; es la prueba de que el poema participa del ser de las cosas, de que constituye una revelación. También es la garantía de que, lejos de ser un devaneo narcisista, trasciende el ámbito subjetivo e individual de su autor para cumplir una vocación de comunicación a los demás, de universalidad:

Porque la piedra de toque de un poema auténtico es la emoción. Eso es lo fundamental. Un poema que no emocione no es para mí un verdadero poema, es decir, no tiene mucho que ver con la poesía mejor. [...] Sentimos al leerlo que hay allí una verdad muy honda, una verdad que no es una ocurrencia del poeta ni pertenece en realidad sólo al poeta, sino que concierne a todos los humanos (2005: 29-30). 


\section{CONCLUSIONES}

La exposición del pensamiento poético de Antonio Carvajal, Miguel d'Ors y Eloy Sánchez Rosillo demuestra que, paralelamente a la concepción “novísima” de la poesía, de inspiración post-estructuralista y deconstructiva, en la generación del 70 se da otra visión del hecho literario, que enlaza con las poéticas de la generación del 50, los poetas de la posguerra, del 27 y de toda la tradición anterior. Según esta visión, el lenguaje se referiría inevitablemente a la realidad, si bien de modo imperfecto, y la creación poética obtendría de ésta los materiales básicos para llevar a cabo su artificio. Además, para Carvajal, d'Ors y Sánchez Rosillo, la poesía no sólo es una actividad que procede de la vida, sino que también puede ejercer su influjo sobre ella. Los tres autores tienen una concepción trascendente del quehacer poético, y le reconocen un poder transformador de la realidad. El vínculo entre poesía, lenguaje y realidad es el que permite la comunicación entre el poeta y sus lectores, con todas las reservas y limitaciones que son lógicas. En el seno de esa relación comunicativa se origina el poder de la poesía para influir en la realidad, a través del estímulo y el consuelo que proporcionan bien la contemplación de la belleza, bien la confirmación de unos valores espirituales determinados, o simplemente la sensación de sentirse comprendido y acompañado. En cualquier caso, la emoción de la auténtica poesía no es nunca una mera distracción o un entretenimiento, sino una revelación que conduce al perfeccionamiento moral o intelectual de quienes la frecuentan.

\section{REFERENCIAS BIBLIOGRÁFICAS}

AMORÓS, A. (1989). “iLos Novísimos y cierra España! Reflexión crítica sobre algunos fenómenos estéticos que configuran la poesía de los años ochenta". Ínsula 512-513, 63-67.

BARELLA, J. (1981). “Poesía en la década de los 70: En torno a los 'Novísimos".' Ínsula 410, 8-10. (1983). "La reacción veneciana: poesía española en la década de los setenta". Estudios Humanísticos 5, 69-76.

CARVAJAL, A. (1982). Servidumbre de paso. Sevilla: Calle del Aire.

(1983). Extravagante jerarquía: poesía 1968-1981. Madrid: Hiperión.

(1993). Miradas sobre el agua. Madrid: Hiperión.

(1995). “Glosas". En Aulaga, Rafael Juárez, 7-12. Valladolid: Fundación Jorge Guillén. (2000). “Los retornos del nómada". En La constancia del nómada: 1960-2000, Jenaro Taléns,

13-15. Valladolid: Fundación Jorge Guillén.

(2001). “Fotografía y poesía". En Literatura y arte, Genara Pulido (ed.), 21-41. Jaén:

Universidad de Jaén.

(2002). “Una reflexión sobre la poesía”. Extramuros 25, 18-19.

(2004a). Los pasos evocados. Madrid: Hiperión. 
(2004b). Poética y poesía. Madrid: Fundación Juan March.

CHICHARRO, A (2002). "La poética conviviente de Antonio Carvajal". Studi Spanici. Poética y poéticas en España e Hispanoamérica 5, 213-223.

GARCÍA, M. (1999). “Entrevista a Antonio Carvajal". Los papeles mojados de Rioseco 1, 32-38.

GARCÍA-MÁIQUEZ, E. (2001)."2001, una odisea en el tiempo". En 2001:poesías escogidas, Miguel d'Ors, 7-30. Sevilla: Cuadernos de Poesía Númenor.

GARCÍA MARTíN, J. L. (1980). Las voces y los ecos. Gijón: Júcar.

GUATELLI-TEDESCHI, J. (2004). La poesía de Antonio Carvajal: consonante respuesta. Madrid: Biblioteca Nueva.

IRAVEDRA, A. (2010). El compromiso después del compromiso. Poesía, democracia y globalización: poéticas 1980-2005. Madrid: UNED.

LANZ, J. J. (1997). Antología de la poesía española (1960-1975). Madrid: Espasa Calpe, 1997. (2011). Nuevos y novísimos poetas en la estela del 68. Sevilla: Renacimiento.

LÓPEZ, I. J. (1990). “El silencio y la piedra: metáforas de la tradición en la poesía española contemporánea". Bulletin of Hispanic Studies 67, 43-56.

MATEO GAMBARTE, E. (2012). “Generaciones literarias”. En Ocho calas en el pensamiento literario español contemporáneo, Eduardo A. Salas (ed.), 127-161. Sevilla: Alfar.

ORS, MIGUEL D' (1972). Del amor, del olvido. Madrid: Rialp. (1994). La imagen de su cara. Granada: Comares. (1999). Hacia otra luz más pura. Sevilla: Renacimiento. (2001). 2001: poesías escogidas. Sevilla: Cuadernos de Poesía Númenor. (2005). Sol de noviembre. Sevilla: Cuadernos de Poesía Númenor. (2008). Virutas de taller: 1995-2004. Valencina: Los Papeles del Sitio. (2010). Sociedad limitada. Sevilla: Renacimiento.

PÉREZ PAREJO, R. (2002). Metapoesía y crítica del lenguaje: de la generación de los 50 a los novísimos. Cáceres: Universidad de Extremadura.

RUBIO, F., y FALCÓ, J. L. (1981). Poesía española contemporánea (1939-1980). Madrid: Alhambra. SÁNCHEZ ROSILLO, E. (1995). Las cosas como fueron. Granada: Comares. (2005a). Poética y poesía. Madrid: Fundación Juan March. (2005b). La certeza. Barcelona: Tusquets. (2008). Oír la luz. Barcelona: Tusquets.

TORÉS GARCÍA, A. (2002). “Encuentro con Antonio Carvajal". Canente. Revista literaria 3-4, 511-517.

Recibido el 20 de enero de 2016.

Aceptado el 27 de octubre de 2016. 
